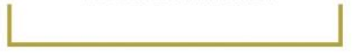

\title{
Pascual Ignacio de Apezechea, los miserables operarios y los díscolos empleados del Apartado de Oro
}

\author{
FELIPE CASTRO GuTIÉRREZ \\ Universidad Nacional Autónoma de México \\ fcastro@,unam.mx
}

\begin{abstract}
Resumen: Este artículo aborda el desempeño de Pascual de Apezechea al frente del Apartado de Oro de la Nueva España como una vía de interés para comprender la compleja naturaleza del trabajo en esta institución. Propone que detrás de la rigidez de las normas existían relaciones clientelares con intercambios de lealtades por apoyos. De esta manera se mantenía el orden, pero en determinados contextos podían ocurrir graves conflictos. La contribución muestra que los problemas mayores no implicaron a los trabajadores manuales sino al personal de supervisión y administración que podía desafiar a sus jefes utilizando a su favor las ambigüedades de las ordenanzas y el hecho de que no eran fácilmente reemplazables. En conjunto, la perspectiva es la de una microhistoria de las relaciones laborales; las fuentes proceden principalmente de documentos de archivo.
\end{abstract}

Palabras clave: Apartado de Oro, Nueva España, Imperio español, conflictos sociales, clientelismo

Recibido: 23 de diciembre de 2020. Aprobado: 24 de abril de 2021. 
El personaje que es asunto de este artículo podría describirse en términos negativos: no fue famoso o especialmente reconocido en su época, no construyó algún palacio que perpetuara su nombre ni fue sujeto de algún retrato hecho por reconocido artista. Tampoco escribió crónicas o tratados de su arte, ni dejó una vasta fortuna que disputaran sus herederos. Su único "gran plan” que podría haberle reservado un lugar en la memoria histórica el de resolver el problema de las inundaciones en la ciudad de México- fue presentado en forma póstuma y no llegó a ninguna parte. ${ }^{1}$ Como se verá tuvo una personalidad flamígera pero esto, aunque ciertamente da para una entretenida narración, podría considerarse como anecdótico.

Pascual de Apezechea (o Apecechea, como a veces también se lo menciona) es de interés por otras razones. ${ }^{2}$ Sin menospreciar los tradicionales ensayos sobre oidores, virreyes y obispos, la historiografía reciente sobre el gobierno indiano se ha interesado en los oficiales del rey de segundo rango. Esto es, quienes aunque ocupaban puestos de discreta responsabilidad eran los que mantenían en funcionamiento los engranajes de la vasta maquinaria del Imperio. ${ }^{3}$ En este caso particular, nuestro personaje estuvo a cargo de una real manufactura sobre las que hay menos conocimiento en relación a las dependencias fiscales o judiciales, tan favorecidas por la historiografía. Se trata del Apartado de Oro, que separaba el metal áureo del argénteo para hacer posible su posterior acuñación. Era una labor compleja y delicada, que

1 Memoria histórica, técnica y administrativa de las obras del desagüe del Valle de México, 1449-1900 (México: Tipografía de la Oficina Impresora de Estampillas. Palacio Nacional, 1902) vol. 1, 256-259. Su proyecto era abrir un foso alrededor de la ciudad y derivar el agua por un canal que saldría por el rumbo de Tlalnepantla; no consideraba conveniente desecar todos los lagos. La propuesta fue presentada varios años después de su fallecimiento, en 1815, por su hermano Fermín, en plena guerra de independencia. Motivó interés, pero fue archivado por irrealizable en las circunstancias reinantes.

2 El personaje se menciona brevemente en un artículo publicado y hay alusiones incidentales en otros trabajos; Felipe Castro Gutiérrez, "Los oficios y los oficiales del Apartado de Oro y Plata, 1776-1821", en Los oficios en las sociedades indianas (México: Instituto de Investigaciones Históricas - Universidad Nacional Autónoma de México, 2020): 188-221. Amerita en sí mismo y por los temas a que conduce un estudio detallado, como espero demostrar.

3 Víctor Gayol, Laberintos de justicia: procuradores, escribanos y oficiales de la Real Audiencia (1750-1812) (Zamora, Michoacán: El Colegio de Michoacán, 2007); Rafael Diego-Fernández Sotelo, María Pilar Gutiérrez Lorenzo, Luis Alberto Arrioja Díaz Viruell, coords., De reinos y subdelegaciones: nuevos escenarios para un nuevo orden en la América borbónica (Zamora, Michoacán: El Colegio de Michoacán - Universidad de Guadalajara - El Colegio Mexiquense, 2014); Michel Bertrand, Grandeza y miseria del oficio: los oficiales de la Real Hacienda de la Nueva España, siglos XVII y XVIII (Zamora, Michoacán: El Colegio de Michoacán - Instituto de Investigaciones Dr. José María Luis Mora - Fondo de Cultura Económica, 2013). 
debía realizarse con la mayor exactitud para beneficio, como entonces se decía, del rey y del público. ${ }^{4}$

Además de este aspecto institucional, la vida profesional de Apezechea permite acceder al conocimiento de conflictos laborales que un administrador más prudente podría haber mantenido en una discreta penumbra. Estaba a cargo de muchos operarios (a los que describía como pobres y miserables, propensos a robos, desórdenes y ebriedades) ${ }^{5}$ así como de varios de los llamados "empleados" o "dependientes", dedicados a la supervisión y administración, que defendían lo que consideraban sus derechos y competían para conseguir mejores puestos.

Las actitudes de Apezechea con el personal bajo su mando fueron a veces ríspidas y arbitrarias, pero también cercanas a un paternalismo que se interesaba por su seguridad, ingresos y la atención de enfermos y ancianos. Parecería en primera instancia una persona contradictoria o de un carácter voluble, pero existía cierta lógica detrás de estos variables comportamientos, como también la había en las quejas y protestas de sus subordinados.

La cuestión es que dichos individuos actuaban de maneras muy variadas frente a las normas, instituciones y jerarquías. Podían aceptar en principio una regla o disposición, pero negociaban por diferentes vías su cumplimiento de acuerdo a sus intereses. Estos aspectos no son anecdóticos: por el contrario, iban moldeando paulatinamente las relaciones de trabajo; cuando se hacían habituales y tolerados podían incidir en las empresas e instituciones e incluso ser considerados como "costumbre", que en el derecho indiano era una fuente supletoria del derecho. ${ }^{6}$ Entre lo general y lo particular, entre lo

4. La separación del oro y la plata requería de un complejo procedimiento químico. Desde el siglo XVI hubo algunos talleres dedicados a esta labor en la ciudad de México y San Luis Potosí. En 1655 la Corona determinó crear y rematar el oficio de apartador, con derechos monopólicos sobre toda la Nueva España. Después de varias herencias y sucesiones acabó en manos de Francisco de Fagoaga, quien estableció talleres en la capital virreinal. En 1778 la Corona tomó la administración directa, indemnizando a los beneficiarios. Víctor Manuel Soria Murillo, "La incorporación del apartado del oro y la plata a la Casa de Moneda y sus resultados de operación, 1778-1805”, Historia Mexicana, 44, 2 (1994): 269-298.

5 Archivo General de la Nación, México (en adelante, AGN), Casa de Moneda, vol. 47, exp. 13, 1808, El Apartador General don Pascual Ignacio de Apezechea sobre que sus dependientes cumplan con lo prevenido en las ordenanzas de aquella Real Casa, f. 283-285.

6 Víctor Tau Anzoátegui, "La costumbre como fuente del Derecho indiano en los siglos XVI y XVII: estudio a través de los Cabildos del Río de la Plata, Cuyo y Tucumán”, III Congreso del Instituto Internacional de Historia del Derecho Indiano: actas y estudios, Madrid, 17-23 de enero de 1972, 1973), 115-192. 
colectivo y lo individual, había siempre un tránsito fluido; no puede comprenderse lo uno sin lo otro.

Asimismo, cuando nos acercamos a las realidades implícitas aparece frecuentemente la relevancia de los vínculos forjados en el origen común. La sociabilidad, el parentesco, el compadrazgo o la conveniencia eran enlaces que recorrían la sociedad tanto horizontal como transversalmente e influían en la manera en que se mantenía (o alteraba) el buen orden.

La única forma de acceder a estas condiciones subyacentes es intentar un acercamiento a la vida y los conflictos cotidianos procurando encontrar prácticas habituales, forcejeos abiertos o sesgados, incluso comentarios y expresiones que a veces podrían pasar por puramente personales o idiosincráticos. De esta manera, cobran sentido situaciones tales como las alusiones a la "pereza" del trabajador, la introducción clandestina de bebidas alcohólicas, los chismes sobre los jefes y las pequeñas intrigas, las complicidades entre operarios y las desobediencias aparentemente menores. No me refiero a alguna especie de "subcultura laboral" porque tanto jefes como empleados compartían un conjunto de ideas; simplemente no les daban la misma interpretación. Más que un espacio de confluencias culturales se trataba de un ámbito de fricciones, imposiciones y negociaciones. ${ }^{7}$

Reconstruir estas historias no es fácil, sobre todo cuando nos remontamos en el tiempo a periodos en que los trabajadores no podían o no estaban interesados en dejar sus opiniones por escrito. Por lo común, tampoco eran asuntos que quedaran registrados en crónicas, actas notariales o memorias, por ello hay que acudir a las menciones laterales e incidentales en diferentes documentos. Cuando es posible, puede llevarse a cabo, como aquí se intenta, una microhistoria de las relaciones laborales. ${ }^{8}$

En este sentido, el estudio de la actuación de Pascual de Apezechea al frente del Apartado ofrece una ventana tan inusual como interesante acerca de la cotidianidad del trabajo, las relaciones jerárquicas, la forma en que se

7 Aproximaciones afines a la aquí propuesta pueden verse en Diego Pulido Esteva, "Trabajo, clase y prácticas policiales en las comisarías de la ciudad de México, 1870-1920”, Historia Mexicana, 68, 2 (2018): 667-712; Susie S. Porter, "Empleadas públicas: normas de feminidad, espacios burocráticos e identidad de la clase media en México durante la década de 1930”, Signos Históricos, 11 (2004): 41-63; Vanesa E. Teitelbaum, "La persecución de vagos en pulquerías y casas de juego en la ciudad de México de mediados del siglo XIX", Historias, 63 (2006): 85-102.

8 George G. Iggers comenta los alcances y límites de esta aproximación, con los riesgos implícitos del anecdotismo y la dificultad de enlazar la "pequeña” y la "gran historia", en Historiography in the Twentieth Century: from Scientific Objectivity to the Postmodern Challenge (Middletown: Wesleyan University Press, 1997), 101-115. 
resolvían los conflictos y ciertas ideas acerca de cómo debía ejercerse la autoridad en un entorno laboral.

\section{Los orígenes}

Pascual Ignacio Eugenio Apezechea Arrieta nació en la montañosa y pequeña villa de Goizueta, en Navarra, en 1751; fue el tercero de ocho hermanos. Su biografía ha sido en cierto sentido eclipsada por la de su más notorio hermano menor, Fermín, quien pasó a la Nueva España en 1777 y logró insertarse muy exitosamente en la ciudad de Zacatecas, por entonces un importante reducto de la colonización vizcaína. Con una combinación de nexos de paisanaje, un buen matrimonio y habilidades personales invirtió en la minería (en La Quebradilla, una empresa que llegó a ser muy próspera). Fue alcalde ordinario de primer voto del ayuntamiento de Zacatecas, representante o “diputado" de los mineros y consultor del Tribunal de Minería, además de dueño de varias haciendas. ${ }^{9}$

De Pascual en estos tempranos años, poco se sabe. Es seguro que llegó antes que su hermano porque decía que en 1777 ya había estado algunos años en Zacatecas: debía por tanto contar algo más de veinte aniversarios. En este real de minas debió tener algún modesto buen nombre porque en 1776 aparece como apoderado general del rico minero José de la Borda; ${ }^{10}$ pero no consta como propietario de alguna mina, comercio o hacienda. Se casó con María Josefa del Barrio Segura, con quien tuvo su primera hija, María Francisca Apezechea del Barrio, bautizada en la ciudad de México en 1778. Luego de enviudar contrajo segundas nupcias con María Ignacia Iturriza Carrillo, también en la capital virreinal. En total tuvo 12 hijos, de los cuales el más conocido fue Pascual Ignacio Apezechea del Barrio, el primer varón, quien fue presidente de la Academia de Artes y vice rector del Real Seminario de Minería. ${ }^{11}$

José Mariano Beristáin, en su Biblioteca Hispano-americana septentrional, dijo que Pascual fue "muy instruido en las matemáticas, en la filosofía y en la

9 Martín Escobedo Delgado, "Cultura material y vida privada. La circunstancia histórica de un minero novohispano”, Memoria XVIII 2005 Encuentro Nacional de Investigadores del Pensamiento Novohispano, Universidad Autónoma de San Luis Potosí; Frédérique Langue, "Mineros y poder en Nueva España. El caso de Zacatecas en vísperas de la Independencia”, Nuevo Mundo - Mundos Nuevos (noviembre 2005) http://journals.openedition.org/nuevomundo/ 1163 (consultado el 14 noviembre de 2020).

10 Frédérique Langue, Mines, terres et société à Zacatecas (Mexique) de la fin du XVIIe siècle à l'indépendance (París: Publications de la Sorbonne, 1992), 135.

11 Seminario de Genealogía Mexicana, "Pascual Ignacio Eugenio Apezechea Arrieta” https://gw.geneanet.org/ (consultado el 15 de noviembre de 2020). 
química y metalurgia”. ${ }^{12} \mathrm{El}$ periodista y escritor Agustín Agüeros se refería en 1906 a él como "persona de vasta ilustración y viajero distinguidísimo que conocía la mayor parte de Europa y una no muy escasa de América”. Citaba una consulta que se le hizo sobre el estado de la ciudad de México; en su respuesta, Apezechea refería su conocimiento de "la Europa” y la provincia de Venezuela. Es una versión que concuerda poco con el joven de Goizueta que pasa a temprana edad a la Nueva España. De momento, sólo puedo hacer notar esta discordancia. ${ }^{13}$

Según su propio relato, Apezechea presenció la gran inundación del valle de México en 1777 cuando iba de Zacatecas a la capital, quizá para recibir a su hermano. En esa ocasión tuvo que dar grandes rodeos, pasar desde Tlalnepantla sobre un acueducto y finalmente caminar por la calzada elevada que partía del santuario de la virgen de Guadalupe. La ciudad, o al menos la ciudad como entonces era, definitivamente no le gustó. Escribió posteriormente que

...es casi imposible dar una idea de lo que era México a los que no lo vieron, sino reduciéndola precisamente a este concepto; que así como en este reino no hay ciudad mayor, tampoco había cenagal más impuro, asqueroso ni más dañoso a la salud ni embriaguez más extendida y libre; ni lascivia con menos recato; ni disolución más desenfrenada con menos empacho; en ninguna parte eran los homicidios, robos, escándalos, y otros insultos más frecuentes; en ningún lugar era menos la reverencia a los templos, a las sagradas procesiones y sacerdotes; ni menos al escarmiento con tan repetidos actos de justicia; ni menos el acatamiento al superior gobierno. ${ }^{14}$

La estancia definitiva de Apezechea en la capital estuvo marcada por su asociación con el médico, matemático y divulgador de la ciencia José Ignacio de Bartolache. Su relación inicial puede haber derivado de recomendaciones o bien de contactos personales mutuos. La tesis de licenciatura y la doctoral de Bartolache (presentadas en 1772) fueron apadrinadas por un importante personaje con intereses en las minas de Zacatecas, Miguel del Berrio Saldívar,

12 José Mariano Beristáin y Souza, Biblioteca Hispano-americana septentrional (ed. facs.) (México: Universidad Nacional Autónoma de México - Instituto de Estudios y Documentos Históricos Claustro de Sor Juana, 1989) vol. 1, 91.

13 Agustín Agüeros, "El virrey $2^{\circ}$. Conde de Revillagigedo en Nueva España. Antecedentes y algunas conclusiones generales", El Tiempo. Diario católico, año XXIV, no. 7826-7839, 20 nov.- 5 dic., 1906 (Folletín de "El Tiempo”, no. 1). Agüeros da como referencia del manuscrito una signatura del Archivo General de la Nación que ya no coincide con la actual; es al presente Historia, vol. 59, exp. 3.

14 Genaro García, Juárez, Refutación a don Francisco Bulnes (México: Instituto Politécnico Nacional, 2007), 130. Hay que tener en cuenta, por otro lado, que se trata de un texto que pretende ensalzar las reformas urbanas realizadas posteriormente por el virrey segundo conde de Revillagigedo. Decía García que esta descripción estaba en un manuscrito en su poder. 
conde de San Mateo de Valparaíso. ${ }^{15}$ No parece excesivo suponer que el conde pudiera conocer a Apezechea durante su estancia en esas minas, dado que además ambos eran vizcaínos.

En 1776 Bartolache entró a trabajar como amanuense en la contabilidad de la Real Casa de Moneda para después desempeñarse como ensayador. Fue designado como primer apartador bajo la administración real directa en 1778 . La labor y la responsabilidad eran enormes: debió recibir los talleres tal como los tenía el asentista Francisco de Fagoaga, adecuar el edificio, crear nuevas ordenanzas, reorganizar la labor y los procesos productivos, establecer un sistema administrativo y contable y, desde luego, rodearse de un personal honesto, capaz y responsable.

En este último contexto se ubica su propuesta de enero de 1783 de colocar en primer lugar en la terna para el nombramiento de ayudante de apartador o "conclavero" a Apezechea, quien por entonces se desempeñaba como amanuense de la fundición de la ceca. ${ }^{16}$ Estos amanuenses no eran simples escribientes, sino que se encargaban también de la administración y la contabilidad; en todo caso era un puesto digno, pero sin mayor relieve. Es algo que sugiere que por alguna razón no había logrado prosperar en Zacatecas, o al menos tuvo razones para alejarse del ámbito de influencia de su hermano, aunque como veremos no se distanció tanto de su apoyo. El superintendente de la ceca, Fernando José Mangino, informó que Bartolache recomendaba la contratación de Apezechea por "las calidades de excelente letra, buena aritmética, conocimiento y manejo de metales y su beneficio por fundición y por azogue en varios minerales del reino". ${ }^{17}$

El conclavero era el segundo cargo en la jerarquía del Apartado; en ausencia o fallecimiento del titular, hacía sus veces. Lo nombraba el virrey a partir de una terna con orden de prelación, a propuesta del apartador y con informe del superintendente. Debía ser confirmado por el monarca, lo cual era engorroso y tardado, pero también un timbre de distinción. ${ }^{18} \mathrm{Al}$ igual que el

15 Roberto Moreno, "El médico José Ignacio Bartolache. 1739-1790”, Ensayos de historia de la ciencia y la tecnología en México (México: Universidad Nacional Autónoma de México, Instituto de Investigaciones Históricas 1986), 49-71.

16 El nombre de conclavero era otorgado a quien guardaba la llave de los distintos talleres. Respecto de los procedimientos para la promoción mediante ternas, véase José María Mariluz Urquijo, "El escalafón administrativo en Indias", Memoria del X Congreso del Instituto Internacional de Historia del Derecho Indiano, tomo 1 (México: Universidad Nacional Autónoma de México, 1995), 807-826.

17 AGN, Casa de Moneda, vol. 440, exp. 2, 1780, Cuaderno formado sobre las Ordenanzas del Real Apartado, f. 98, 100r.

18 Respecto a la Real Casa de Moneda y su relación institucional con el Apartado, véase Víctor Manuel Soria Murillo, La Casa de Moneda de México bajo la administración borbónica, 1733-1821 (México: Universidad Autónoma Metropolitana, 1994); Felipe Castro Gutiérrez, Historia social de la Real Casa de 
apartador, tenía rango de "ministro", como quien hacía cumplir la real voluntad del monarca en un ámbito particular de la administración pública. Por eso se especificaba que el ayudante debía ser "no sólo inteligente en este género de operaciones de química y metalurgia, sino de un porte y conducta acreditada e irreprensible”. Estaba a cargo de disponer todas las operaciones cotidianas que se efectuaban en el taller, asignar ocupación a los subalternos y distribuir el trabajo a los operarios, todos los cuales debían mostrarle respeto y obediencia. A veces se le mencionaba como un "interventor" de las cuentas del apartador, dado que tenía también que firmarlas para certificar su veracidad. Recibía por su labor 1200 pesos anuales, más una vivienda en el propio establecimiento. ${ }^{19}$

Las relaciones entre Bartolache y Apezechea fueron de una amistosa colaboración, que fue más allá del Apartado en sí. En 1787 fue Apezechea uno de los testigos en la inspección del lienzo de la Virgen de Guadalupe, realizada bajo la dirección de Bartolache como parte de una averiguación de perspectiva científica que le trajo muchos sinsabores. También fue el mecenas de una reproducción de la imagen guadalupana hecha por el pintor Rafael Gutiérrez, porque se quería comprobar la durabilidad del lienzo. ${ }^{20} \mathrm{Y}$, en fin, cuando (de manera póstuma) salió impreso el Manifiesto satisfactorio... Opúsculo guadalupano de Bartolache (1790), los dos hermanos Apezechea aparecieron entre los subscriptores de la obra, es decir, quienes la habían adquirido por adelantado y ayudado así a sufragar la edición. ${ }^{21}$

Tuvo Bartolache también una iniciativa científica-empresarial: las "píldoras marciales” (un suplemento férrico). En 1787 informaba en la Gaceta que las únicas pastillas "auténticas" eran las expedidas por persona de su confianza y a su vista en la botica de Antonio Arvide. La "persona de su confianza” era, precisamente, Apezechea. ${ }^{22}$

\section{El conclavero}

Moneda de México (México: Universidad Nacional Autónoma de México, Instituto de Investigaciones Históricas, 2012).

19 Fabián de Fonseca y Carlos de Urrutia, Historia general de Real Hacienda (ed. facs.) (México: Secretaría de Hacienda y Crédito Público, 1978), vol. 1, 290.

20 José Ignacio de Bartolache, Manifiesto satisfactorio anunciado en la Gaceta de México, Opúsculo guadalupano (México: Zúñiga y Ontiveros, 1790), pieza no. 1. http://cdigital.dgb.uanl.mx/la/10800 14953/10800 14953_12.pdf (Consultado el 25 de noviembre de 2020).

21 Bartolache, Manifiesto satisfactorio, 16.

22 Clementina Díaz y de Ovando, "La Nueva España al alborear el siglo XIX (Ciudad de México 1801)”, Anales médicos, 45, 4 (2000): 206. 
Cuando Bartolache tomó la dirección del Apartado, había seis empleados de supervisión y dirección, así como 16 jornaleros u operarios que ganaban cuatro reales por día, aunque obtenían un "sobre jornal" cuando hacían operaciones pesadas y complejas o que requerían horas extraordinarias. Escribió al superintendente que los operarios no recibían el salario correspondiente a pesar de que exponían su salud en una jornada de 12 horas en condiciones muy insalubres. El superintendente Mangino contestó que no podía modificar los jornales sin consultar al virrey, y en lo inmediato dispuso que se diera a los trabajadores un peso mensual adicional como gratificación. ${ }^{23}$

No se quedó satisfecho el apartador, y en diciembre de 1784 apoyó una idea que hizo constar le había presentado su conclavero Apezechea. La propuesta era entregar a los jornaleros (que pasarían a ser 22) una cantidad fija diaria, hubiera o no labores, suprimiendo los pagos por horas extraordinarias y las gratificaciones. Al mismo tiempo, establecía diferencias de ingresos según una nueva jerarquía (de capitán, ayudante, operarios diestros, "no tan diestros", "comunes" y mujeres lavadoras). El fin era que los operarios "modernos" (esto es, de reciente ingreso) apetecieran promoverse de la clase de comunes a la de diestros por medio de su aplicación y los de esta segunda clase "se alienten y estudien en adiestrarse más y más aspirando a la capitanía”, dado que antes, al ganar todos igual, no tenían aliciente para hacerlo. Consideraba que así se favorecería tanto a los trabajadores como al establecimiento, porque cuando no había labores tenían que ganarse el pan como albañiles o arrieros y se dificultaba volver a reunirlos; había ya ocurrido que se quedara sin los más expertos y tuviera que reemplazarlos por bisoños. Agregaba que los mismos operarios se habían allanado a esta forma de pago y aún le instaban para que se pusiera en aplicación. En cuanto a los costos, estimaba que habría una diferencia de 487 pesos anuales, que bien se compensaría con una mayor eficiencia y producción.

El contador de la Casa de Moneda no pareció muy convencido de estos cálculos, y fuese por esta u otra razón la propuesta no prosperó. No fue sino hasta enero de 1788 que varios operarios insistieron ante el superintendente para que se pusiera en ejecución el plan que Bartolache, compadeciéndose de sus necesidades y reclamos (según decían), había propuesto. El apartador incluso indicó que él y sus dependientes inmediatos ofrecían ceder formalmente hasta un tercio de sus salarios para cubrir cualquier cargo

23 AGN, Casa de Moneda, vol. 388, exp. 5, 1778, Sobre la incorporación de la real corona del oficio de Apartador General de oro y plata de estos reinos y agregación a esta Real Casa de Moneda, f. 303r-305r. 
adicional que sufriera la Real Hacienda..24 Así se aprobó, y es frecuente que en diversos momentos posteriores se aludiera al "Plan de jornales" para aceptar o denegar alguna pretensión. Es difícil saber qué parte provenía de Apezechea y cuál de Bartolache, pero hay que notar que el primero debía tener algún conocimiento del trabajo en las minas, y en el Apartado estaba en comunicación directa con los jornaleros.

$\mathrm{Al}$ fallecimiento de Bartolache (9 de junio de 1790), Apezechea quedó a cargo de manera interina. Por su experiencia, evidentemente esperaba ser designado como siguiente apartador con lo que pasaría a recibir unos atractivos 5000 pesos anuales. ${ }^{25}$ Sin embargo, la sucesión no fue fluida ni fácil. El ahora superintendente, Francisco Fernández de Córdova, informó que, aunque Apezechea podría dirigir el Apartado, el establecimiento era susceptible de mejoras y ahorros. Dirigió entonces una carta al muy respetado director del Seminario de Minería, el científico Fausto de Elhuyar, proponiéndole el puesto. Elhuyar rehusó cortésmente, alegando sus varias obligaciones y compromisos con el rey, pero ofreció sus conocimientos para perfeccionar las operaciones.

En vista de esto, el superintendente pergeñó un plan muy complicado. En lugar de nombrar un apartador, se designaría a Elhuyar como director facultativo (sin tener que renunciar a la dirección de Minería) con un salario de 1500 pesos. Estaría encargado de dirigir y perfeccionar todas las labores y operaciones y de enseñar física, química y metalurgia, durante las temporadas que residiera en la capital, a varios jóvenes de talento que serían escogidos por el mismo superintendente entre los empleados de las oficinas de contaduría y tesorería de la Casa de Moneda. Apezechea quedaría como administrador general, sujeto a Elhuyar, con 3500 pesos anuales de sueldo; en vez de conclavero se nombraría a un contador interventor interino, con 1000 pesos anuales, con todo lo cual además resultaría un ahorro para la Real Hacienda. El plan fue aprobado por el virrey Revillagigedo y se expidieron los respectivos nombramientos. Elhuyar aceptó el encargo, con las debidas gracias por la confianza con que le honraban. ${ }^{26}$

24 AGN, Casa de Moneda, vol. 488, exp. 540, 1784, El Apartador General sobre que se acuda con las asignaciones diarias en lugar de los jornales que gozan, $\mathrm{f}$. 11.

25 Desde el punto de vista formal no era forzoso. Las ordenanzas no preveían requisitos para ocupar el puesto. El superintendente presentaba una terna al virrey para el nombramiento del apartador quien, como era común en esos casos, designaba al primero de la lista. El monarca posteriormente confirmaba el nombramiento. Fonseca y Urrutia, Historia general de Real Hacienda, vol. I, 287.

26 AGN, Casa de Moneda, vol. 411, exp. 1, 1790, Proyecto provisional para la dirección y gobierno del Apartado General de Oro y Plata, y nombramiento de apartador en favor de Pascual de Apezechea, f. 4-15. 
La idea era interesante: equivalía a crear una escuela técnica y práctica bajo la dirección de un reconocido científico, lo cual ciertamente habría sido una notable e inédita innovación educativa. Provocó sin embargo una gran agitación en el Apartado y algunos oficiales presentaron una queja formal ante el rey, alegando incluso que su honor había resultado afectado. Apezechea, de hecho, fue llamado al real palacio para ser amonestado por varias expresiones "indecorosas". ${ }^{27}$ Hay que tener en cuenta que al darse una promoción en el establecimiento quedaban vacantes consecutivas que iban siendo ocupadas por quienes tenían la plaza inmediata inferior. Es posible, además, que se resintiera la llegada a un puesto de autoridad de alguien ajeno al establecimiento, dispuesto a implantar imprevisibles novedades.

Podría haberse solventado el caso por un acto de autoridad, pero la innovación fue desaprobada en Madrid. El 23 de julio de 1791 una real orden reprendió al virrey por haber aceptado un procedimiento contrario a las ordenanzas, comunicó que en el proceso habían existido varias irregularidades y que la propuesta hecha a Elhuyar debía haberse consultado previamente al monarca. Se mandaba proveer a Apezechea como apartador general, como se hizo el 16 de noviembre de 1792, sujeto a la real confirmación. ${ }^{28}$

El superintendente tomó a mal que se rechazara su proyecto. En su escrito de respuesta explicó que no pretendía ignorar las ordenanzas, y que se había dado "contraria inteligencia a mi plan interino por fines e intereses particulares disfrazados con el especioso pretexto del mejor servicio del rey, graduando de injusticias los efectos de una providencia meramente económica”. Era particularmente duro con Apezechea, a quien consideraba sin méritos, habría procedido de mala fe, era incapaz de actuar de manera parcial y desinteresada, y era quien había movido a los demás a protestar por los nuevos nombramientos. ${ }^{29}$

El conflicto no terminó aquí. Apezechea escribió posteriormente que

27 AGN, Reales Cédulas Originales, vol. 149, exp. 256, Manda sea reprendido don Pascual Ignacio Apezechea, 23 de julio 1791, f. 396rv. Estas expresiones incluso fueron en contra del difunto apartador Bartolache. No constan las razones del enojo de Apezechea en contra del hombre de quien había sido asociado y cercano colaborador. Podría caber la idea de que alguna opinión previa del apartador hubiera incidido en los planes del superintendente para no concederle la promoción, pero es una simple especulación.

28 AGN, Casa de Moneda, vol. 411, exp. 1, 1790, Proyecto provisional..., f. 25; AGN, Casa de Moneda, vol. 46, exp. 14, 1792, Nombramiento de apartador general para Pascual Ignacio de Apezechea, f. 162-198.

29 AGN, Casa de Moneda, vol. 411, exp. 1, 1790, Proyecto provisional... f. 25, 55a$64 a$. 
al tiempo de colocarme yo en el empleo de apartador general de este reino se me levantó una poderosa persecución y se le sugirieron a su excelencia [el virrey Revillagigedo] eficaces influjos e informes contra mi aptitud, acompañándolo todo especiosas propuestas. Su excelencia no pudo menos que oponer toda su autoridad y poder a mi colocación e informar al soberano que convenía desatenderla y proveer la plaza como se le proponía. Pero habiéndose dignado su excelencia de visitar esta oficina y logrado yo instruirle en mi justicia, conoció y confesó haber sido engañado. ${ }^{30}$

Después de muchas idas y venidas, Apezechea recibió la confirmación de su título de apartador y siguió ocupando el cargo hasta su fallecimiento, el 22 de junio de 1812.31 Entre sus fiadores estuvieron Gabriel Pérez de Elizalde (un gran comerciante del tráfico con Filipinas) y Manuel de Retegui, socio de Fermín de Apezechea en la mina La Quebradilla, ambos vizcaínos. ${ }^{32}$

Su largo periodo al frente del establecimiento proporcionó (a pesar de algunos "detalles" que comentaremos) continuidad, confianza en la buena práctica contable, seguridad en la ley de los metales y coincidió con una época de notable expansión de la producción. ${ }^{33}$ No debió ser labor fácil, porque debía atender simultáneamente los complejos procedimientos del apartado de metales, el mantenimiento y ampliación del edificio, el abasto de materias primas, y el reclutamiento, promoción y supervisión de empleadores y operarios.

Solamente hubo en este periodo un par de momentos complicados. En septiembre de 1795 el superintendente hizo constar que había una demora en las labores del Apartado. Podía llegar incluso al caso de que se detuviera enteramente la compra de platas mixtas (esto es, las que contenían oro) porque el fondo previsto para ese fin se agotaría, sin que hubiera un reintegro en forma de las barras de plata y tejos de oro que resultaban del apartado de

so Agüeros, “El virrey $2^{\text {o. }}$ Conde de Revillagigedo en Nueva España”. El asunto de las malas relaciones entre el superintendente y el apartador llegó a preocupar al sucesor de Revillagigedo, el marqués de Branciforte. Este virrey mandó formar un extracto de todos los documentos (que llegó a ser de doce cuadernos) con el mayor sigilo, "para no dar lugar a odiosidades, rencores y desavenencias, de que podrían originarse irreparables daños”. De esto no salieron más que algunas decisiones sobre puntos muy concretos y una recomendación a su sucesor, Azanza, de que se instruyera sobre el asunto. Anselmo de la Portilla, Instrucciones que los virreyes de la Nueva España dejaron a sus sucesores (México: Imprenta de Escalante, 1878), vol. II, 594-596.

31 AGN, Casa de Moneda, vol. 465, exp. 7, 1812, Sobre la paga del sueldo devengado por el apartador general don Pascual Ignacio de Apezechea hasta el día de su fallecimiento, f. 51-53.

32 Las fianzas eran indispensables para todo puesto que manejara caudales del rey. AGN, Casa de Moneda, vol. 661, exp. 87, Subrogación otorgada por Manuel de Retegui...; Escobedo Delgado, "Cultura material”.

33 Soria Nieto, "La incorporación del Apartado”, 286-294. 
los metales. Envió al contador y al escribano de la ceca al Apartado para realizar una "visita formal", que equivalía a una inspección, y era, desde luego, un acto de desconfianza.

Apezechea resintió la reprobación implícita a su labor y en su respuesta pidió al superintendente que "se sirva mandar se deje de preocupar al público con falsas ideas y de lastimar mi honor atribuyéndome defectos en que yo no he incurrido". Explicó que el rezago se debía a que se estaban realizando obras de adecuación y ampliación del edificio, por lo cual había sido necesario detener las labores. Señaló asimismo algunos problemas con la producción del vidrio debido a la carencia de hornos, la calidad de algunas materias primas y el descuido de los operarios. Para salir del atraso propuso varias medidas paliativas. El superintendente dio su visto bueno y el expediente no continúa, lo cual indica la suspensión o fin de esta inspección. ${ }^{34}$ En perspectiva, pudo deberse tanto a una preocupación concreta como un medio para el superintendente de mostrar quién mandaba.

La otra coyuntura difícil ocurrió en marzo de 1812, cuando las fundiciones estuvieron a punto de detenerse por falta de leña para los muchos hornos del establecimiento. La razón era que había algunas partidas de insurgentes en las inmediaciones de la ciudad, y los proveedores no se atrevían a recorrer los caminos. De todos modos, los trabajos habían disminuido considerablemente porque casi no llegaban metales de las minas. ${ }^{35}$

\section{El Apartado}

No pueden comprenderse cabalmente las situaciones institucionales y laborales del Apartado sin considerar la compleja naturaleza de sus labores. Inicialmente, se siguieron los procedimientos establecidos bajo la administración privada. Básicamente consistían en fundir en un crisol una porción de plomo (que permitía eliminar impurezas, como azufre o cobre), algo de cobre y luego el oro y la plata, en una proporción que debía ser aproximadamente de 1:3. Tras esto, se vertía la mezcla fundida en un barreño o caldero con agua para obtener granalla, o sea un granulado. Luego se colocaba la granalla en una redoma de vidrio y se añadía aguafuerte, una disolución de ácido nítrico en cantidades variables de agua que disolvía la plata, pero no el oro. Se hervía a fuego indirecto y moderado durante varias

34 AGN, Casa de Moneda, vol. 81, exp. 8, Expediente formado para averiguar las causas de que dimana el atraso de labores en las oficinas del Real Apartado, 1795, f. 178-195.

35 AGN, Casa de Moneda, 1812, vol. 148, exp. 33, Superior oficio sobre que se tomen las providencias más eficaces a fin de activar las operaciones del Real Apartado. 
horas; cuando dejaba de echar humos rojos y éstos pasaban a blanco, se vertía la mezcla en otra vasija en la que ahora estaba disuelta la plata. En el fondo de la redoma original quedaba el oro en forma de un polvo obscuro. El proceso volvía a repetirse una o dos ocasiones para separar los últimos residuos de plata. Después se enjuagaba el polvo de oro sucesivas veces para eliminar las sales condensadas del aguafuerte, hasta que el agua saliera clara e insípida. Cuando el oro estaba seco, se recocía en un crisol agregándole atincar (borato sódico), y un poco de solimán (cloruro de mercurio) para hacerlo más maleable.

El aguafuerte y el "agua de plata" de los enjuagues se destilaban posteriormente en dos recipientes de vidrio unidos por sus bocas, llamados cornamusas, con lo que se recuperaba gran parte del solvente y quedaba la plata en forma de sedimento. Las cornamusas se quebraban para recuperar el metal. Finalmente se fundían por separado el oro y la plata, y se vertían en moldes de piedra para formar barras y tejos que se llevaban a la Casa de Moneda para su acuñación. ${ }^{36}$

El Apartado también realizaba operaciones secundarias pero indispensables. El aguafuerte se hacía empleando colpa (un óxido que contenía algo de "alumbre" o sulfato doble de aluminio y potasio), al cual se le agregaba salitre. Los ingredientes se mezclaban en botellas de vidrio revestidas de barro para evitar que se resquebrajaran por el fuego. Se ponían en un horno y se cubrían con un capelo de alambique, durante un día y medio. Los vapores conectaban con una cornamusa de vidrio, en cuyo interior se condensaba y goteaba el producto de la destilación. ${ }^{37} \mathrm{El}$ aguafuerte era distinto al "agua regia", "ácido marino" o salfumán: este último resultaba cuando la base era el ácido clorhídrico con parte menor de nítrico, y tenía la propiedad de disolver el oro sin afectar la plata; no se empleaba en el Apartado.

La producción de vidrio era una fuente constante de atención y preocupación para los apartadores, por su necesidad y gran consumo. Un ingrediente para la manufactura era la llamada "hierba barrilla" (salsola kali), que crecía en las orillas de los lagos del norte del Valle de México; con su calcinación se obtenía sosa. Asimismo, se requerían cuarzos que se obtenían de arena de pedernal traída de Tlalpujahua. La mezcla o "pasteladura" se vaciaba en

36 Bernardo Muñoz de Amador, Arte de ensayar oro, y plata, con breves reglas para la theorica y la práctica... (Madrid: Imprenta de Marín, 1755), 201-204. Varios aspectos dudosos fueron resueltos en el trabajo enciclopédico de Guillermo Céspedes del Castillo, Las casas de monedas en los reinos de Indias. Las cecas indianas en 1538-1825 (Madrid: Fábrica Nacional de Moneda y Timbre, 1996), 129. Un resumen en Castro Gutiérrez, "Los oficios", 177-179.

37 Alonso Barba, Arte de los metales en que se enseña el verdadero beneficio de los de oro y plata por azogue, el modo de fundirlos todos, y cómo se han de refinar y apartar unos de otros (Madrid: Viuda de Fernández, 1770), 183-185. 
moldes de piedra. Una vez obtenida la masa vítrea, el oficial vidriero extraía con una larga varilla hueca lo suficiente para cada pieza, soplando para darle la forma deseada. Finalmente se utilizaban pinzas y otras herramientas para modelar y unir los detalles. ${ }^{38}$

Los procesos que implicaban fundición de metales dejaban desechos (hollín, cenizas, grasas, derrames): al conjunto se le llamaba "tierras" y contenía algo de plata. También el vidrio quebrado que resultaba de varios procesos contenía restos aprovechables de metales fundidos. Todo se molía en una rastra o molino rústico, con un eje conectado a cadenas que movían grandes rocas prismáticas, jalado por mulas. A la mezcla se le añadía poco a poco agua hasta obtener una lama. Se procedía entonces a un cernido y lavado para eliminar los desechos gruesos, y lo restante se procesaba mediante fundición o azogue, según conviniera, al igual que se hacía en las minas. El metal resultante se regresaba al proceso productivo. ${ }^{39}$

Apezechea organizó todos estos procesos con eficiencia y cuidado. En los documentos consta que recorría los talleres de manera cotidiana para vigilar que todo se realizara con presteza y exactitud. Por otro lado, no se mostró muy afecto a aceptar nuevas técnicas. Por ejemplo, rechazó algunos experimentos realizados por el guardavista Miguel Álvarez, calificándolos de extravagantes; prefería lo que llamaba "el antiguo método". ${ }^{40}$ También se ocupó de dar una opinión negativa sobre las innovaciones propuestas en el libro L'art d'essayer l'or et l'argent de Balthazar Georges Sage (1780), que había sido traducido y enviado a México para que fuese considerada su utilidad. Entre otros peritajes (como el del Tribunal de Minería) se pidió el dictamen de Apezechea, quien opinó que los ensayos realizados localmente eran más exactos, y la fabricación de aguafuerte se hacía con menor costo. ${ }^{41} \mathrm{~A}$ lo sumo, bajo su dirección se realizaron en el establecimiento pruebas para encontrar la manera de mejorar algunos procedimientos menores y específicos, sin alentar ninguna modificación radical.

Esta renuencia al cambio fue probablemente lo que estuvo en la mente del superintendente cuando dijo que el Apartado era susceptible de mejoras y

38 José Roberto Peralta Rodríguez, "Materia prima, hornos y utillaje en la producción de vidrio de la ciudad de México, siglo XVIII”, Estudios de Historia Novohispana, 58 (2018): 13-25.

39 AGN, Casa de Moneda, vol. 46, exp. 19, El Apartador General propone que se beneficien las tierras..., f. 242-251.

40 AGN, Casa de Moneda, 1807, vol. 79, exp. 2, Miguel Álvarez, guardavista del Real Apartado y José González, oficial cuarto de la Contaduría de la Aduana, sobre permutar sus destinos, f. 14-15.

${ }_{41}$ Alberto M. Carreño, Compendio de la historia de la real hacienda de Nueva España, escrito en el año de 1794 (México: Imprenta y Fototipia de la Secretaría de Industria y Comercio, 1914), 227-228. 
Apezechea no era el más indicado para impulsarlas. Alejandro de Humboldt, quien visitó el establecimiento en 1803, opinó que los procesos estaban lejos de la perfección que habían alcanzado en Inglaterra y Francia, y que podrían beneficiarse de los adelantos de la mecánica y la química. ${ }^{42}$

No puede cerrarse esta sección sin mencionar el carácter riesgoso y muy insalubre de las labores. Los humos fétidos que desprendían las chimeneas eran la razón de que el establecimiento se hallara fuera de la "traza" de la ciudad española, en el barrio de indios de San Sebastián y en un rumbo poco poblado. El apartador mencionaba que "la malignidad de los vapores corrosivos del agua fuerte, los humos y efluvios de los metales que se funden y el continuo fuego de tantos hornos en la asistencia de doce o más horas diarias, es la frecuente y forzosa causa de que se inhabiliten y enfermen los empleados". ${ }^{43}$

\section{El edificio}

Una de las preocupaciones constantes de los apartadores fue el mantenimiento y ampliación del edificio, que ya tenía más de un siglo. Cuando Bartolache tomó posesión de la dirección del Apartado, el inmueble de la calle de la Acequia tenía varios talleres: de separación de metales, con 11 hornos y 22 hornillas; otro para afinación y fundición de barras de plata y tejos de oro; un gran taller para fabricación de piezas de vidrio con sus correspondientes hornos; otro para destilación de aguafuerte y solimán, con cinco hornos; un taller para preparación de colpa; un molino de hierba barrilla; una bodega de salitres; corrales para guardar leña y un par de viviendas en la parte alta. Varias de esas dependencias eran de calicanto, pero otras de adobes y techadas con vigas y tejamanil, a pesar del evidente riesgo que implicaba la multiplicidad de hornos. ${ }^{44}$ La única adecuación realizada bajo su gobierno fue la demolición en 1785 de unos "jacalones" o bodegas viejas, donde se edificaron talleres para un tercer horno de vidrio, ocho de aguafuerte y cinco de destilación de plata, además de la construcción de bodegas para materias

42 Alejandro de Humboldt, Ensayo político sobre el reino de la Nueva España (París, Casa de Rosa, 1822), vol. 4, 31-34.

43 AGN, Casa de Moneda, vol. 47, exp. 11, 1789-1796, Expediente formado en virtud de varias representaciones del Apartador General sobre aumento de empleados en sus oficinas, f. 195-197v.; AGN, Casa de Moneda, vol. 74, exp. 11, 1817-1819, Los guardavistas del Real Apartado sobre que se les abone las horas extraordinarias..., f. 138-174.

44 AGN, Casa de Moneda, 1778, vol. 388, exp. 5, Sobre la incorporación de la Real Corona del oficio de Apartador General del oro y plata, f. 251. 
primas, materiales diversos y otras ampliaciones. Todo estuvo a cargo del maestro mayor Francisco Guerrero y Torres. ${ }^{45}$

Se trataba de modificaciones que respondían a urgencias inmediatas y necesidades concretas, pero el edificio aún no cumplía con los requerimientos de una planta industrial, con un diseño racional para acomodar los diferentes talleres. El caso más evidente de la obsolescencia y de los riesgos asociados ocurrió el 2 de septiembre de 1796, cuando se partió la viga de madera que sostenía el techo de tejamanil del taller del vidrio y todo se vino abajo con gran estruendo y confusión. El resultado fue de 12 operarios lesionados de gravedad atendidos en diferentes hospitales con traumatismos y quemaduras; al final tres fallecieron y uno quedó baldado.

Apezechea se movió prestamente para afrontar las consecuencias, despejar la sala de trabajo y reparar el daño. Se encargó también de que se pagaran 2 reales diarios vitalicios a una viuda y dos madres de fallecidos, así como 3 reales diarios vitalicios al impedido. En la averiguación judicial subsecuente se atribuyó el accidente al efecto del continuo calor de los hornos sobre la madera, y no se le fincaron responsabilidades por el derrumbe. Fue preciso reconstruir el taller, ahora con una bóveda de mampostería. ${ }^{46}$

En 1808, después de mucho insistir, Apezechea logró que se le adjudicaran fondos para adquirir unas viviendas contiguas donde se construirían de nuevo los talleres de destilación de plata, hornillas de apartar metales y molinos de colpa. La obra corrió a cargo del afamado arquitecto Manuel Tolsá. ${ }^{47}$

En 1810 el apartador obtuvo el presupuesto para una reestructura general del edificio, con la creación de una nueva oficina de tierras, con tres rastras; dos hornos, un patio para el beneficio de azogue, tanques y pilas para el lavado, un aposento para la dirección del taller y una bodega para herramientas y materiales. Entre otros arreglos estuvieron los nuevos "comunes" o sanitarios, dos viviendas para el apartador y el conclavero, y una

45 AGN, Casa de Moneda, vol. 190, exp. 2, 1785, Expediente sobre la construcción de un horno de vidrios, ocho para aguafuerte y cinco para destilación en el Real Apartado, f. 57-230.

46 El incidente ha sido descrito en Alberto Soto Cortés, Reina y soberana. Una historia sobre la muerte en el México del siglo XVIII (México: Universidad Nacional Autónoma de México, 2019), 145-158. La documentación al respecto se halla en AGN, Casa de Moneda, vol. 81, exp. 20, 1796, Expediente formado sobre haberse hundido el techo de vigas de la oficina de hornos de vidrio del Real Apartado, s. 289-425; y AGN, Casa de Moneda, vol. 81, exp. 21, 1706, Expediente formado a consulta del Apartador General sobre que se acuda con algún socorro vitalicio a un operario que quedó lastimado..., f. 426-442.

47 AGN, Casa de Moneda, vol. 121, exp. 8, 1808, Sobre que se fabriquen de nuevo las oficinas de hornos de destilación de plata y hornillas de apartar, f. 94-107. 
capilla dedicada a la Virgen de Guadalupe. Todo tuvo el costo de 38.830 pesos y también estuvo a cargo de Tolsá. Las obras se concluyeron en $1813 .{ }^{48}$

\section{El personal}

Otro aspecto indispensable para el buen desempeño del apartador era rodearse de hombres de confianza, comenzando con el ayudante conclavero quien debía ser su mano derecha e indispensable encargado de organizar las labores cotidianas. El primero, en 1792, fue Antonio Jiménez de Arenal. Es interesante señalar que su fianza fue proveída entre otros por el hermano del apartador, Fermín de Apezechea. ${ }^{49}$ Este hecho y el que lo hubiera preferido a pesar de que este oficial arrastraba serios padecimientos (disentería y úlceras intestinales) parece indicar que realmente lo apreciaba. Arenal pidió varias licencias para reponerse, incluso de cuatro meses, además de un adelanto de 500 pesos sobre su sueldo, que le fueron concedidos sin mayor objeción. En octubre de 1798 había fallecido, insolvente y con una deuda de 100 pesos con el Apartado. ${ }^{50}$

En junio de 1799 Apezechea propuso y se nombró a José Ramón de los Cobos, quien había desempeñado el puesto de conclavero de manera interina en las frecuentes ausencias de Jiménez. Era natural del real de Asientos de Ibarra, que llevaba su nombre en honor de los conquistadores y colonizadores vizcaínos Francisco y Diego de Ibarra. Apezechea fue muy enfático al recomendarlo. ${ }^{51}$ Además de sus conocimientos y experiencia, es probable que ser originario de un real de minas en la órbita zacatecana no estorbara.

Al fallecimiento de Cobos en junio de 1811, como veremos, la sucesión al puesto de conclavero fue muy agitada. El cargo finalmente no recayó en quien Apezechea prefería en primera instancia, sino en un oficial de larga trayectoria en la Casa de Moneda y el Apartado, Joaquín María Casarín, quien pertenecía a una familia con varios miembros al servicio de la institución. Casarín llegaría posteriormente a ser apartador durante el

48 AGN, vol. 465, exp. 5, 1811 , Sobre la fábrica de nueva oficina de beneficio del Real Apartado. f. 17- 39. Aparece reseñado en Francisco de la Maza, "Algunas obras desconocidas de Manuel Tolsá”, Anales del Instituto de Investigaciones Estéticas, IV, 14 (1946): 37-39.

49 AGN, Casa de Moneda, vol. 661, exp. 84 y 85, 1794-1795.

50 AGN, Casa de Moneda, vol. 148, exp. 4, 1798, Ocurso del ayudante conclavero Antonio Jiménez de Arenal, sobre que le suplan por vía de anticipación 500 pesos..., f. 80-108.

51 AGN, Casa de Moneda, vol. 148, exp. 7, 1789, Sobre provisión del empleo de ayudante conclavero del Apartado vacante por fallecimiento de Antonio Jiménez de Arenal, f. 115-136. 
complicado periodo entre 1812 y 1828, cuando tuvo lugar la revolución de independencia y luego la transición al México republicano.

Un tema que preocupó a Apezechea fue la escasez general de personal, tanto de los operarios como de los empleados de supervisión y administración. El problema era que las ordenanzas fijaban el número de contratados. Así, para aumentar las plazas era necesario obtener el parecer favorable del fiscal de la Real Hacienda (que solía opinar negativamente) y la licencia del virrey, siempre presionado por las demandas metropolitanas de más recursos fiscales que sostuvieran los gastos de la Corte.

Apezechea argumentó que los trabajadores eran pocos, no era fácil reclutar a quienes fuesen capaces y, además, era frecuente que se ausentaran por enfermedad. Logró que se le autorizara contratar tantos eventuales como fuese necesario cada día, lo cual implicaba modificar el "plan de jornales". Esto creó una categoría permanente de operarios "de afuera" a los que se pagaba "por cuadernillo", esto es, según jornadas trabajadas. ${ }^{52}$

Un asunto distinto y más complejo era el de los amanuenses, que se encargaban de la contabilidad, y sobre todo de los guardavistas. Estos últimos eran una especie de sobrestantes o capataces encargados de dirigir los procesos productivos y supervisar a los operarios de los talleres, sin que tuvieran ubicación fija. Los proponía el apartador, hacía un informe el superintendente y los nombraba el virrey. No podían ser depuestos por el apartador, sino que en su caso debía enviar un informe reservado al superintendente explicando las causas y razones. Se distinguían y ordenaban entre el primero (que ganaba 1200 pesos al año) y el cuarto (que obtenía 800). Tanto para protegerse como para mostrar su dignidad, podían portar armas blancas en público. ${ }^{53}$

La ampliación de la producción llevó a Apezechea a gestionar y lograr que se contratara a un guardavista quinto en 1791 , con 700 pesos de sueldo ${ }^{54}$, pero ni aun así era suficiente. Para solventar las urgencias inmediatas se contrataban guardavistas "supernumerarios" o interinos, que en principio trabajaban sólo cuando eran demandados pero que en la práctica se convirtieron en otra categoría de empleados, presentes de manera continua. Apezechea no estaba satisfecho con esta solución porque le parecía que con lo poco que se les pagaba solamente se presentarían hombres inhábiles, que se resignarían a trabajar por cuatro o cinco pesos a la semana. También tenía conocido que quienes contaban con experiencia renunciaban cuando

52 AGN, Casa de Moneda, vol. 47, exp. 11, 1789, Expediente formado en virtud de varias representaciones..., f. $186 \mathrm{v} .-187$.

53 Fonseca y Urrutia, Historia general de Real Hacienda, v.1, 290-293.

54 AGN, Casa de Moneda, vol. 47, exp. 11, 1789-1796, Expediente formado en virtud de varias representaciones..., f. 177-178. 
encontraban una labor menos pesada y mejor retribuida; no podían esperar a que se pusiera a concurso una de las plazas "propietarias”, que usualmente se abrían sólo a la muerte del titular. Quería que se les pagara siete pesos por semana, y dos pesos cada día al que trabajara en los hornos de vidrio. Su solicitud tuvo el apoyo del superintendente pero la oposición del fiscal de Real Hacienda. En abril de 1802 se le contestó con un seco "no ha lugar por ahora”. ${ }^{55}$

\section{Un apartador de genio violento e intrépido}

Lo que hasta ahora he descrito del desempeño de Apezechea es lo que, en términos generales, podría esperarse del jefe de un departamento celoso del desempeño de su institución. Pero, por otro lado, tenía modos de tratar a sus subordinados que dan la imagen de un personaje que podía ser arbitrario y propenso a exabruptos.

Los operarios lo respetaban, pero también le temían. En 1800 ocurrió que faltaban vidrieros conocedores del oficio. Por esta razón Apezechea trajo un maestro de ese arte, José María Piza, para que enseñara el oficio a tres jornaleros, prometiéndole 150 pesos por esta labor. Piza cumplió con lo prometido, pero cuando se presentó a reclamar su recompensa Apezechea le dijo “anda, quítate de aquí y no seas loco” volteándole al mismo tiempo la espalda. El maestro vidriero no se atrevió a reclamar la gratificación. No fue sino años después, en 1819, ya fallecido el apartador y él mismo enfermo e imposibilitado de trabajar, que se presentó con testigos para solicitar la retribución prometida. ${ }^{56}$

Por otro lado, Apezechea podía tener actitudes que podrían describirse como paternalistas. Ya hemos visto su participación en el plan de jornales, que al menos en la versión oficial tuvo el apoyo de los operarios y les aseguraba un sustento diario. En otros momentos mostró preocupación porque se realizaran obras para que el taller del vidrio tuviera mejor ventilación, porque tal como estaba era en grave perjuicio y daño de los trabajadores. ${ }^{57} \mathrm{Y}$ en varias ocasiones medió en favor de los que llamaba "miserables y ancianos operarios”, que habían servido fielmente durante muchos años pero no tenían ninguna vía formal para recibir alguna pensión. Intervino para que obtuvieran algún "socorro" mientras vivieran, porque pensaba que era de

55 AGN, Casa de Moneda, vol. 47, exp. 11, 1789-1796, Expediente formado en virtud de varias representaciones..., f. 265-271 (El expediente 11 se interrumpe, y prosigue después del número 12 del mismo volumen).

56 AGN, vol. 31, exp. 16, 1819, José María Piza, oficial de vidriero del Real Apartado, sobre que se le satisfagan 150 pesos de gratificación..., f. 183-191.

57 AGN, Casa de Moneda, vol. 302, exp. 6, 1800, Sobre la necesidad de dar ventilación a la oficina de los hornos del vidrio del Apartado, f. 119-134. 
justicia premiar a los operarios que no gozaban de sueldos fijos, cuando la vejez o las enfermedades los imposibilitaban. ${ }^{58}$ En algún caso declaró que, si se negaba el auxilio, estaba dispuesto a pagarlo de su bolsillo. 59

El problema para Apezechea era cuando la conducta de los subordinados ponía en cuestión su autoridad, o parecía tener fines ulteriores. El ejemplo más interesante, porque remite a lo que era un ambiente laboral muy tenso, ocurrió en octubre de 1800. El apartador tuvo una discusión con José Vicente Ramírez, operario del taller del vidrio, quien le parecía que mostraba una "maliciosa flojera" y llevaba las cargas al horno con un paso deliberadamente lento, al punto que detenía a los demás. Después de discutir con él, perdió la calma, tomó un leño de los que se guardaban para aprovisionar los hornos y se lo arrojó a la cabeza, causándole una aparatosa herida. El trabajador se quejó ante el superintendente, como juez particular que era de la Casa de Moneda.

Apezechea dijo que no se trataba más que de un ligero rasguño, que el quejoso quería ganar su salario sin trabajar y que detrás de la demanda estaba quien le tenía trastornada la oficina, pero no nombraba para que no padeciera su honor; y que lo que querían era incomodarle, meter cizaña y "desconceptuarlo" con el superintendente. Había empleados ineptos y díscolos, según decía, que habían conseguido inquietar a los operarios. Si antes sólo con su presencia se avivaban en la labor, ahora no se movían ni con súplicas ni con reconvenciones. De hecho, hacía méritos de que a pesar de tener él un "genio violento e intrépido" fuera el único caso que se hubiera presentado. El querellante no volvió a mover su causa, por lo cual el superintendente mandó archivarla. ${ }^{60}$

\section{Los díscolos empleados}

La razón de los conflictos entre el apartador y esos "díscolos" cuyo nombre no quería mencionar era básicamente un forcejeo por las contrataciones, promociones y obligaciones cotidianas de los empleados, que dependían del parecer del apartador y la decisión del superintendente.

Similares cuestiones se derivaban de las labores atribuidas a cada guardavista. Aunque en principio estaban claramente delimitadas, también había casos en

58 AGN, Casa de Moneda, vol. 45 1, exp. 9, 1799, Ocurso de Bernardo Aguilar, maestro de vidriero del Real Apartado..., f. 164-173.

59 AGN, Casa de Moneda, vol. 451, exp. 7, 1798, Ocurso de Joseph de la Encarnación Muñoz, operario del Real Apartado, f. 120-151.

60 AGN, Casa de Moneda, vol. 148, exp. 29, 1808, Ocurso de José Vicente Ramírez, operario del Real Apartado, sobre haberle causado una herida en la cabeza el Apartador General con un leño, f. 394-405. 
donde se las describía en términos muy generales, para así poder incluir distintas e imprevisibles situaciones concretas. Esto podía ser muy práctico y razonable, pero cuando había un conflicto cabían distintas interpretaciones.

El precipitante fue el problema aparentemente menor de sustituir al portero en sus ausencias. Este empleado vigilaba la puerta y acompañaba el carretón que transportaba las barras de plata y oro a la Casa de Moneda para su posterior acuñación, auxiliándose del piquete de soldados que siempre vigilaba la entrada del establecimiento. Además, se encargaba de revisar las pertenencias y el mismo cuerpo de los trabajadores (hasta sus partes "más ocultas") cada vez que entraban o salían del establecimiento; el propósito era evitar que introdujeran bebidas alcohólicas y precaver cualquier posible robo. Este aspecto muy físico de la labor de los porteros hacía que se asimilara su cargo a los oficios "viles" y contrarios al honor de las personas, por lo cual muchos empleados no querían ocuparse de ella. La ordenanza cuidaba de declarar específicamente que el portero "no está vilmente ocupado" y debía considerarse "persona decente", lo cual muestra que había una preocupación al respecto. ${ }^{61}$ Agréguese un lado práctico: además de que su horario era muy pesado (de las cinco de la mañana a las diez de la noche) los porteros eran responsables de tener los hornos con la "calda" adecuada a las seis de la mañana, cuando comenzaban las labores, para lo cual tenían que estar en pie a las dos y media o tres de la mañana. Esto acontecía aproximadamente dos veces por semana. Por esta razón residía en el mismo edificio, en un pequeño espacio en el entresuelo.

Como era inevitable, el portero no podía estar día y noche en su labor. A veces pedía tiempo para ir a misa, se reportaba enfermo o iba a cumplir diversos encargos de sus jefes. En estos años, el portero era ya anciano, lo cual hacía que sus ausencias fuesen más frecuentes de lo habitual. Apezechea había solicitado que se nombrara un suplente, pero no se le aceptó; se dispuso que, en caso necesario, un guardavista supliera al portero, aunque esto obviamente implicaba que no estaría vigilando alguno de los talleres. ${ }^{62}$

61 Fonseca y Urrutia, Historia general de Real Hacienda, vol. IV, 293. El tratadista Aznar de Polanco definía la "arte sórdida”, comúnmente llamada "vil" como "aquella que sin más actos especulativos se adquiere solamente por la repetición de una simple y material práctica y corporal ejercicio, en bajas, humildes y poco decentes operaciones; que por esto se llama sórdida, porque mancha, humilla y ensucia el esplendor del sujeto en la calidad y en la persona”. Juan Claudio Aznar de Polanco, Arte nuevo de escribir por preceptos geométricos, y reglas mathematicas (Madrid: Imprenta de los Herederos de Manuel Ruiz de Murga, 1719), 10.

62 AGN, Casa de Moneda, vol. 47, exp. 11, 1789-1796, Expediente formado en virtud de varias representaciones..., f. 176-197v. 
Los guardavistas titulares preferían que la incómoda obligación de sustituir al portero la desempeñara un guardavista supernumerario. $\mathrm{O}$ bien, que para velar por las noches se contratara a alguien para ese efecto y caso particular. Estas opciones no eran bien vistas por el apartador, porque evidentemente las labores y responsabilidades quedaban a cargo de personas que no tenían la misma experiencia.

Todas estas situaciones podían haberse resuelto de manera adecuada entre el apartador y los guardavistas con una combinación de autoridad y negociación, pero Apezechea disponía lo que le parecía conveniente y exigía obediencia sin preocuparse del descontento ni cuidarse de las posibles consecuencias.

Un incidente característico ocurrió con el amanuense Gabriel Palacios (1797). Apezechea lo acusó de faltar por tiempos prolongados sin dar aviso, haber dicho que las ordenanzas no le obligaban y comportarse "como moro sin señor" (esto es, sin reconocer ninguna autoridad). Pensaba que debía procederse severamente en su contra, porque "si desde el principio no se destruye la mala semilla que va a producir tan perversa cizaña, después cuando se ha arraigado y se alegue la tolerancia y costumbre, será imposible remediarlo". El superintendente debió tener otra opinión del empleado y las razones del conflicto, porque lo resolvió arreglando su traslado a la administración del palacio virreinal. ${ }^{63}$

Es difícil saber hasta qué punto había una "perversa cizaña" o se trataba de una reacción excesiva de Apezechea frente a protestas y resistencias menores. Sin duda le resultaban inaceptables, y es posible que esto estuviera detrás de una sorprendente iniciativa suya. En noviembre de 1804 propuso al virrey que se le entregase el Apartado en arrendamiento, con un detallado proyecto para su operación. Aunque la figura jurídica (que vendría a ser una especie de "asiento") no era la misma que la de la venta de oficios, habría implicado volver a los tiempos en que el Apartado estaba en manos privadas. Lo más probable es que Apezechea buscara tener una mayor independencia, y también mayor autoridad frente a sus subordinados, a los que ahora podría despedir cuando le pareciera.

En su opinión, el superintendente comentó que le parecía chocante que un oficial del rey ofreciera tomar en arrendamiento las oficinas que tenía a su propio cargo, cuando debía utilizar su talento, práctica y conocimientos para promover su aumento y mejoras. De Apezechea decía que lo consideraba como un ministro "aplicado y activo, y con bastantes conocimientos prácticos”, pero que tenía un genio demasiado duro, por lo cual no sacaba el

63 AGN, Casa de Moneda, vol. 47, exp. 11, 1789-1796, Expediente formado en virtud de varias representaciones..., f. 237-239. 
partido que podría obtener de sus subalternos y provocaba que sus ásperas consultas o representaciones a los superiores no fuesen aceptadas. No volvió a hablarse del asunto. ${ }^{64}$

Los incidentes ríspidos entre el apartador y sus empleados no dejaron de ocurrir mostrando así el serio deterioro de la relación laboral. Por ejemplo, en septiembre de 1807 el tercer guardavista, Miguel Álvarez, solicitó una permuta de su empleo con un oficial de la Real Aduana. Explicaba que no tenía ya la resistencia para el esfuerzo de 12 horas continuas de asistencia en el Apartado y que con el cambio "quedará el servicio del Rey desempeñado y nosotros consolados de la benignidad de vuestra excelencia”.

Apezechea informó que el solicitante tenía razones para pedir la permuta que ocultaba cuidadosamente, porque le haría poco honor confesarlas: criticaba a su jefe por ignorante, tenía la cabeza llena de ideas ridículas sobre un nuevo método de apartar metales, había tratado incluso de "alucinar" con sus propuestas al superintendente y causado con sus experimentos serios trastornos en el taller del vidrio, además de que se ausentaba sin permiso. Se negaba a aceptar la permuta, quería que renunciara para poner en su lugar a alguien capaz.

El superintendente comentó que en otro tiempo Apezechea se había referido a Álvarez en términos muy elogiosos. Pensaba que tenían resentimientos personales difíciles de conciliar porque, como decía, “ambos son vizcaínos", lo cual parece haber querido decir que eran tercos y orgullosos. Consideraba que Álvarez tenía prendas apreciables y podría servir al rey en otra oficina, como finalmente se aprobó. ${ }^{65}$

\section{La insubordinación de 1808}

En abril de 1808 Apezechea se quejó ante el superintendente por los actos de insubordinación de varios guardavistas. Se trataba de José Salvador Hidalgo, quien a pesar de ser el más "moderno" (esto es, el de menor antigüedad) se negaba a suplir al portero y cuando lo hacía se quedaba metido en la "covacha" (un pequeño espacio junto a la puerta, donde se mantenía el portero) sin registrar a los que entraban y salían, con lo que había dado lugar a robos, introducción de bebidas, embriaguez "y otros excesos y maldades". Asimismo, se agraviaba de otros guardavistas: Juan Bautista Echegoyen, quien había faltado durante 15 días; Miguel Álvarez, que estaba resentido

64. AGN, Casa de Moneda, vol. 148, exp. 23, 1804, Expediente relativo al de la propuesta hecha por el Apartador General Pascual Ignacio de Apezechea de que se le entregase en arrendamiento el Apartado, f. 240-244.

65 AGN, Casa de Moneda, vol. 79, exp. 2, 1807, Miguel Álvarez, guarda de vista del Real Apartado..., f. 9-23. 
porque no le había aceptado varios proyectos ridículos; José Cristóbal Rodríguez y Toribio García, quienes también se rehusaban a suplir al portero "por presunción y vanidad". Aunque no lo mencionó, los denunciados se habían visto en el pasado favorecidos por él con recomendaciones elogiosas para pasar de supernumerarios a titulares o conseguir sus promociones.

Es complejo saber si Apezechea estaba simplemente desahogando frustraciones acumuladas en contra de prolongados y constantes desafíos a su autoridad, o si se trataba de maniobras y actitudes concertadas de los empleados para hacerle la vida difícil a su jefe. Así parecía verlo el apartador, quien aseveró que los denunciados querían servir a su antojo, sin sujeción a sus órdenes, de modo que había tenido que poner a cargo de la delicada oficina del vidrio a un guardavista supernumerario sin experiencia. Pedía al superintendente que tomara providencias para que se sujetaran, cumplieran y obedecieran; y que a su ayudante y segundo en el mando, el conclavero José Ramón de los Cobos, se le diera a entender que debía ser más activo y celoso, porque para no malquistarse con los guardavistas les disimulaba todo y no lo apoyaba en sus providencias. El superintendente, quien evidentemente no quería meterse en un espinoso asunto, se limitó a mandar que los empleados cumplieran puntualmente con sus labores. ${ }^{66}$

Esta muy general disposición evidentemente no resolvía el conflicto. El 4 de mayo Apezechea comunicó que había separado a Hidalgo de su cargo debido a su altanería e insubordinación, porque se había negado a ocuparse de la portería -a pesar de recibir una orden al respecto- alegando que sólo debía suplir al portero en caso de enfermedad. El superintendente, sin embargo, le respondió que según la ordenanza no podía despedir por sí mismo a un guardavista, y lo que debía haber procedido era un informe para que él dispusiera lo conveniente; de momento debía restituir a Hidalgo en su puesto. Por otro lado, ordenó que todos los dependientes obedecieran al apartador en lo concerniente al real servicio, con apercibimiento de que se procedería contra el que así no lo verificare. Si alguno de ellos tenía que representar sobre el asunto, podrían hacerlo juntos o por separado, con moderación y respeto.

Era una disposición que, como se ve, tomaba distancias de las partes en conflicto y procuraba mantener la buena marcha de los talleres, pero que difícilmente podía ser vista como un respaldo contundente a la autoridad del apartador. Apezechea protestó e insistió en la separación de Hidalgo en

66 AGN, Casa de Moneda, vol. 47, exp. 13, 1808, El Apartador General don Pascual Ignacio de Apezechea..., f. 277-281. Varias de las pasadas promociones y recomendaciones de los quejosos aparecen en Sobre provisión del empleo de ayudante conclavero del Apartado... 1798, AGN, Casa de Moneda, vol. 148, exp. 7, f. 123-124. 
términos que llevaron al superintendente a notificarle que debía expresarse "en términos más moderados y decorosos". ${ }^{67}$

Como el superintendente les había permitido presentar sus quejas directamente ante él, varios guardavistas alegaron que la ordenanza especificaba que no tendrían ocupación o lugar fijo, pero esto no incluía explícitamente el "servicio de puerta", al que en su opinión debían destinarse los suplentes. Después de ver todos los autos, así lo aceptó el superintendente el 4 de junio. Apezechea lo tomó muy a mal. Dijo que lo determinado modificaba una práctica de 30 años establecida por su antecesor Bartolache y que los guardavistas ahora estaban tan ufanos y confiados en la protección del superintendente que "no me entiendo con ellos pues cada uno hace lo que quiere sin reconocerme para nada”. Actuaban, en suma, en desprecio de su empleo y su persona. Pidió que se reconsiderara la decisión y se mantuviera lo que llamaba "el método antiguo", que era de notoria utilidad al real servicio, más conforme al espíritu de las ordenanzas y menos gravoso para los empleados.

Esta representación motivó una prolongada información de oficio en que se llamó a declarar a varios pasados guardavistas. Todos concordaron en que, cuando el portero se hallaba inhabilitado u ocupado en otros menesteres fuera de las oficinas, era el sargento de guardia quien se ocupaba de vigilar la puerta. El asesor dictaminó el 27 de septiembre que el apartador estaba en un error, porque el método y costumbre que había alegado se había interrumpido en varias ocasiones, de modo tal que "no pueda fundarse en él o ella un derecho imprescriptible que tenga valor o fuerza de ley como otras costumbres legítima e invariablemente introducidas”. Opinó que debía ratificarse lo ordenado, sin permitirse más informes o reclamos, y así se dispuso.

Lo único que consiguió Apezechea fue que a los supernumerarios se les aumentara el jornal de 8 a 12 reales, al igual que a los titulares, porque no le parecía justo que se les recargara el trabajo con más obligaciones, y se corría el riesgo de que solamente aspiraran al puesto hombres poco calificados o de constitución demasiado débil para soportar las fatigas del trabajo. ${ }^{68}$

\section{Genio y figura...}

67 AGN, Casa de Moneda, vol. 47, exp. 13, 1808, El Apartador General don Pascual Ignacio de Apezechea..., f. 290-295.

68 AGN, Casa de Moneda, vol. 47, exp. 13, 1808, El Apartador General don Pascual Ignacio de Apezechea..., f. 309-330. 
En junio de 1811 falleció el conclavero José Ramón de los Cobos, por lo cual Apezechea procedió a formar la terna de candidatos que por reglamento debía presentar al virrey, con informe del superintendente. Propuso, en orden de prioridades, a Juan Miguel Sistiaga, oficial escribiente del Apartado; a su propio hijo el guardavista José María Apezechea; y a Leandro Mujica, empleado en la contaduría de la Real Casa de Moneda. ${ }^{69}$ Esto provocó quejas del guardavista tercero, nuestro ya conocido José Salvador Hidalgo y del guardavista segundo Juan Bautista Echegoyen, porque se consideraban desplazados de sus legítimos méritos.

Según Hidalgo, los propuestos no tenían experiencia ni capacidad, y se le hacía un agravio al no tenerlo en cuenta; no dejó de observar que la aparición en la terna de un familiar era algo irregular, dado que las ordenanzas mandaban que no hubiese parientes en una misma oficina. El escrito de Echegoyen fue aún más estridente: sostuvo que Apezechea estaba "maquinando arbitrios" para colocar a su hijo, y que todo se debía a que desde hacía ocho años no quería entregar cuentas de su gestión para que no se descubrieran sus fraudes. El superintendente observó que era intolerable el modo "altanero, mordaz y picante" con que se expresaba Echegoyen respecto de su jefe. ${ }^{70}$

La respuesta de Apezechea fue un escrito en un tono muy medido para terminar después, cuando el expediente se alarga y complica, en una nota flamígera. Sostuvo que podía proponer para el puesto a quien le pareciera mejor, sin que la antigüedad en sí fuese el criterio preponderante. Propuso reformular la terna, dejando en primer lugar a Joaquín María Casarín, un respetado oficial que había permanecido al margen del litigio. Se agravió de que los quejosos se habían comportado con ligereza, falta de verdad y desacato a su autoridad. Respecto de Echegoyen, argumentó que no era apropiado que permaneciera en el establecimiento un subalterno de notoria mala conducta, díscolo y que descaradamente se atrevía a desacreditar a su jefe inmediato, llevado por un espíritu de venganza. Había llegado al extremo de decirle en público, en su cara, que no se detendría hasta conseguir que él y su hijo fuesen privados de sus empleos. Como dijo: “iNo sé cómo tuve paciencia para sufrirlo! ¡Su fortuna fue que no tuviese yo alguna arma a la

69 El caso se refiere brevemente en Castro Gutiérrez, "Los oficios...", 174-175. La documentación al respecto se halla en AGN Casa de Moneda, vol. 46, exp. 6, 1811, Por muerte de José Ramón de los Cobos, ayudante conclavero del Real Apartado, se presentan a solicitar la plaza..., f. 34-127.

70 AGN Casa de Moneda, vol. 46, exp. 6, 1811, Por muerte de José Ramón de los Cobos..., f. 51-52. 
mano porque en tal caso creo me pierdo vengando en su sangre tanta injuria!”. ${ }^{71}$

Las quejas hicieron ver mal a Apezechea, y el fiscal de Real Hacienda a quien el virrey remitió el caso, llegó a solicitar una averiguación formal sobre su conducta y manejos. Sin embargo, las informaciones pedidas se detuvieron porque, como consta en el expediente, el apartador estaba demasiado enfermo, y poco después se dejó constancia de que había fallecido. ${ }^{72}$

El deceso de Apezechea parece haber dejado la idea de que se le había tratado mal, o al menos así lo pensaban las personas en posición de autoridad. Echegoyen se presentó humildemente ante el superintendente a declarar que se sujetaba a su juicio si era merecedor de la plaza y lamentaba que su señoría se hubiera sentido con él. Al fin del expediente consta que pedía un traslado a otras oficinas de la Real Hacienda en el lejano Sombrerete (en Zacatecas), porque, como comentó el superintendente, ya no podía servir en el Apartado sino con disgusto “y acaso con vergüenza”. ${ }^{73}$

A la viuda de Apezechea, María Ignacia, se le permitió seguir viviendo en la casa que ocupaba en el Apartado a pesar de que en rigor ya no le correspondía; la razón fue que su cuñado, el influyente minero Fermín, interpuso "sus respetos" y el superintendente dio su aprobación en vista de los extraordinarios servicios prestados por su difunto marido. ${ }^{74}$ En cuanto a su hijo, José María, siguió sirviendo en el Apartado acumulando méritos y llegó a ser nombrado apartador en 1829, puesto en que continuó hasta 1849, cuando el gobierno y administración del establecimiento se fusionaron con el de la Casa de Moneda. ${ }^{75}$

\section{Conclusiones}

La eficiente y a la vez conflictiva trayectoria de Pascual Ignacio de Apezechea al frente del Apartado del oro tiene varios aspectos dignos de consideración.

71 AGN, Casa de Moneda, vol. 46, exp. 4, 1811, El virrey Venegas ordena al apartador..., f. 19-29v.

72 AGN, Casa de Moneda, vol. 46, exp. 6, Por muerte de José Ramón de los Cobos..., f. 74-76.

73 AGN, Casa de Moneda, vol. 46, exp. 6, 1812, Por muerte de José Ramón de los Cobos..., f. 34-127. Sin embargo, las circunstancias debieron cambiar, porque aparece en años posteriores trabajando en el Apartado.

74. Allí continuó algunos años hasta que el guardavista encargado del taller del vidrio reclamó una vivienda que por reglamento él debía ocupar, AGN, Casa de Moneda, 1817, vol. 74, exp. 4, f. 29-41.

75 AGN, Casa de Moneda, 1829, vol. 12, exp. 25, 1828, Fallecimiento del apartador general don Joaquín María Casarín y encargo de sus funciones a don José María Apezechea, f. 247-280. 
Fue en muchos sentidos atípica, porque en general se esperaba que los responsables de la administración virreinal consiguieran mantener el orden y la armonía en sus respectivas dependencias.

Esta historia muestra la presencia e importancia de ciertas ideas implícitas, que sólo pueden advertirse en una aproximación a casos y situaciones particulares. Las relaciones entre un jefe y sus subordinados en el Apartado no eran puramente formales e impersonales. Aunque era un establecimiento regido por normas racionales y adscrito a una estructura burocrática, el ejercicio concreto de la autoridad era afín a una relación clientelar, en la que se intercambiaban lealtad y servicios por tutela y auspicio. Esto, como vimos, no cambió enteramente con Apezechea, que, si bien en algunas ocasiones se refirió a los operarios manuales en términos bastante despectivos, en otras mostró interés en ayudar a algunos hombres viejos o enfermos, que habían servido fielmente durante muchos años. De hecho, las fricciones más notables no ocurrieron con los jornaleros, como podría haberse esperado en una primera aproximación a la historia social del establecimiento.

Otra cosa fue, como hemos visto, sus relaciones con los empleados de supervisión y administración. Por un lado, se ocupó de reclutar y recomendar a personas de su confianza, aunque no siempre con los resultados esperados. Por otro, sus relaciones con el personal llegaron a ser difíciles por cuestiones de promoción y condiciones de trabajo. Estas diferencias podrían haberse resuelto con una combinación de actos de autoridad, concesiones y promesas, pero esto no ocurrió así. Apezechea no encontraba la obediencia que consideraba debida; sus subordinados resentían la falta de voluntad (la "benignidad") para atender algunas de sus demandas. Las reciprocidades deseadas en esta relación dejaron de estar presentes. Hubo obviamente temas específicos, pero en la aspereza de los conflictos puede verse una ruptura en las expectativas de conductas mutuamente esperadas.

Hay otros aspectos que influyeron en las difíciles interacciones del apartador con los empleados. Como se recordará, su periodo de dirección comenzó con mal pie cuando no fue designado para el puesto que podía esperar se le adjudicara, como mano derecha que había sido de Bartolache. Era algo que devaluaba sus méritos y lo dejaba expuesto como alguien que no tenía la completa confianza de sus superiores. Las posteriores tensas relaciones con el superintendente y los momentos en que este jefe dio la razón a sus subordinados en una disputa por las condiciones de trabajo debieron contribuir al debilitamiento de su autoridad.

Debe tenerse también en cuenta que los empleados tenían una posición en la que hasta cierto punto podían enfrentarse al apartador, si llegaban a considerarlo conveniente o necesario. Como hizo constar el propio Apezechea, eran personas que tenían los conocimientos y la experiencia 
necesarias para llevar a cabo operaciones complejas y delicadas; no era fácil sustituirlos. Tampoco podía destituirlos a su voluntad, sino que debía presentar un informe al superintendente para que éste decidiera; era algo que no se escapaba a nadie. Normalmente, no debería haber sido problema si el apartador y el superintendente hubieran estado en buena armonía, pero como se vio, esto no fue siempre así.

En conjunto, la actuación de Apezechea y los muchos sinsabores por los que pasó muestran que los subordinados podían, en ciertas circunstancias, confrontarse a sus superiores con cierto éxito cuando veían afectados sus intereses y conveniencias. Podían llegar a alegar en su beneficio -como se habrá apreciado- la “costumbre”, esa misma que al apartador consideraba que una vez establecida sería difícil de desarraigar. No se trataba de un enfrentamiento abierto, que habría atraído sanciones, sino un continuo flujo de quejas y demandas que acabaron por poner en difícil situación al apartador. El caso expone relaciones laborales complejas, que hacen evidentes los límites de la autoridad, la existencia de ideas subyacentes en las relaciones jerárquicas, así como las fricciones y rupturas que podían ocurrir en un establecimiento en principio bien regulado. 
Title: Pascual Ignacio de Apezechea, the Miserable Workers and the Wayward Employees of the Apartado de Oro

Abstract: This article addresses the performance of Pascual de Apezechea at the head of the Apartado de Oro of New Spain, as a way of understanding the complex features of work in this institution. Behind the rigid ordinances, it argues, there were clientelist relationships which implied the exchange of loyalties for support. This practice allowed to keep order, but in certain situations serious conflicts emerged. This article shows that major problems did not involve manual workers but members of the management staff. They could challenge their bosses recurring to the ambiguities of the regulations and the fact that they were not easily replaceable. Overall, the article proposes a microhistory of labor relationships; the sources come mainly from archives.

Keywords: Apartado de Oro, New Spain, Spanish Empire, social conflicts, clientelism

Titulo: Pascual Ignacio de Apezechea, os trabalhadores infelizes e os empregados desobedientes do Apartado de Oro

Resumo: Este artigo aborda o desempenho de Pascual de Apezechea como chefe do Apartado de Oro da Nova Espanha como uma forma interessante de entender a natureza complexa do trabalho nesta instituição. Propõe que por trás da rigidez das regras havia relações clientelísticas com trocas de lealdades para apoio. Desta forma, a ordem foi mantida, mas em certos contextos poderiam ocorrer graves conflitos. A contribuição mostra que os maiores problemas não envolviam trabalhadores manuais, mas pessoal supervisor e administrativo que podia desafiar seus chefes usando as ambigüidades das portarias e o fato de que elas não eram facilmente substituíveis em seu benefício. Em geral, a perspectiva é a de uma micro-história de relações industriais; as fontes provêm principalmente de documentos de arquivo.

Palavras-chave: Apartado de Oro, Nova Espanha, Império Espanhol, conflitos sociais, clientelismo 